\title{
Synthesis and Characterization of Ni-doped Silica Membranes Prepared Using a Hybrid Sol-Gel/CVD Method
}

\author{
Sadao Araki, ${ }^{* 1,2}$ Hiroyuki Yano, ${ }^{1}$ Shunsuke Tanaka, ${ }^{1,2}$ and Yoshikazu Miyake ${ }^{1,2}$ \\ ${ }^{1}$ Department of Chemical, Energy and Environmental Engineering, \\ Faculty of Environmental and Urban Engineering, Kansai University, \\ 3-3-35 Yamate-cho, Suita, Osaka 564-8680 \\ ${ }^{2}$ High Technology Research Center, Kansai University, 3-3-35 Yamate-cho, Suita, Osaka 564-8680
}

(Received July 1, 2011; CL-110553; E-mail: araki_sa@kansai-u.ac.jp)

Improving the hydrogen permeation flux, while maintaining high hydrogen selectivity, is important for reducing membrane areas and enhancing membrane reactor (MR) performance. We have attempted to enhance the hydrogen permeation through the addition of nickel, which will improve both hydrogen adsorption and pore size control. The silica layer was deposited with high selectivity, using an extended counter-diffusion CVD method.

Hydrogen is widely used in chemical and petroleum industries and has been predicted to be a clean fuel for polymer electrolyte fuel cells (PEFCs) in the future. More than the half the hydrogen worldwide is produced from the steam reforming (SR) of natural gas, whose main feedstock is methane. ${ }^{1}$ In this reaction, by-product gases, such as carbon dioxide, carbon monoxide, and methane, in addition to hydrogen, make up the reforming gas. Therefore, much research has been focused on separation technologies, such as membrane separation. Of the primary membrane materials, silica has attracted much attention, owing to its high heat stability and low production cost.

Recently silica-based membranes, which have high hydrogen permeance and high selectivity, have been prepared using a hybrid processing method that combines the sol-gel and CVD methods. ${ }^{2}$ In this study, a Ni-doped silica membrane is prepared using a hybrid method involving the sol-gel and high-pressure CVD methods. Ni-doped silica layers were prepared on $\alpha$-alumina support with a $\gamma$-alumina interlayer, using the solgel method. We have attempted to enhance hydrogen permeation through the addition of nickel, which is expected to improve the hydrogen adsorption and pore size control. Silica membranes with a high selectivity were subsequently prepared using counter-diffusion CVD, under high-pressure conditions at the membrane side, where tetramethylorthosilicate (TMOS) is supplied.

An $\alpha$-alumina tube $(10 \mathrm{~mm}$ o.d., $6 \mathrm{~mm}$ i.d., $35 \mathrm{~mm}$ length, Noritake Co., Ltd.) with a $\gamma$-alumina layer was used as the membrane substrate. The porous $\alpha$-alumina tube ( $35 \mathrm{~mm}$ length) was joined to a dense $\alpha$-alumina tube $(10 \mathrm{~mm}$ o.d., $6 \mathrm{~mm}$ i.d., $250 \mathrm{~mm}$ length) and an $\alpha$-alumina disk (12 mm diameter, $2 \mathrm{~mm}$ thickness) with a glass sealant. The $\gamma$-alumina interlayers were prepared by dipping $\alpha$-alumina tubes into a $0.6 \mathrm{~mol} \mathrm{~L}^{-1}$ boehmite $(\gamma-\mathrm{AlOOH})$ sol, containing $1.5 \mathrm{wt} \%$ poly(vinyl alcohol). The tube was dried at room temperature for $3 \mathrm{~h}$ and then calcined at $600^{\circ} \mathrm{C}$ for $3 \mathrm{~h}$, at a heating and cooling rate of $1^{\circ} \mathrm{C} \min ^{-1}$.

Tetraethoxysilane (20 g, Wako) was added after all the nickel(II) nitrate hexahydrate $(\mathrm{Ni} / \mathrm{Si}$ mol ratio $=0.5,0.25$, and 0 ) had dissolved in ethanol. $1 \mathrm{M} \mathrm{HNO}_{3}(7.5 \mathrm{~mL})$ was added dropwise to the mixture with gentle stirring at room temperature over a period of $15 \mathrm{~min} .{ }^{3,4}$ The temperature was then increased to $70^{\circ} \mathrm{C}$ and the mixture was heated at reflux for $150 \mathrm{~min}$. The resulting solution was diluted to $0.1 \mathrm{~mol} \mathrm{~L}^{-1}$ in ethanol. The membrane substrate was dipped into the nickel-silica solution for $10 \mathrm{~s}$. Finally, the membrane was dried at room temperature for $3 \mathrm{~h}$ and calcined at $873 \mathrm{~K}$ for $3 \mathrm{~h}$.

The silica was deposited using counter-diffusion CVD with tetramethoxysilane, TMOS (Kishida Chemical), and oxygen for $1 \mathrm{~h} .{ }^{5}$ The temperature was raised to $873 \mathrm{~K}$ under an argon atmosphere. After reaching $873 \mathrm{~K}$, the TMOS was introduced to the outside of the $\alpha$-alumina tube, bearing a $\gamma$-alumina interlayer, under an argon carrier gas at a flow of $200 \mathrm{~mL} \mathrm{~min}^{-1}$. Oxygen was then introduced to the inside of the $\alpha$-alumina tube. The pressure of the TMOS feed side was adjusted to $0.2 \mathrm{MPa}$ using a back-pressure regulator.

Gas permeation experiments were performed for a range of temperatures at a differential pressure of $0.1 \mathrm{MPa}$, using nitrogen as sweep gas. The measurement gas was fed inside the tubular membrane, with a nitrogen feed-rate outside the membrane offset to $20 \mathrm{~mL} \mathrm{~min}^{-1}$. The flow rates for the sweep gas and the permeated gas were measured using bubble flow meters, and the concentrations of the gases were determined using a gas chromatograph equipped with a thermal conductivity detector (GC-8A, Shimadzu, Japan). The permeance was then calculated based on the flow rate and the concentration of the measurement gas.

The relationship between temperature and both the hydrogen permeance and hydrogen selectivity over methane for the typical membranes is shown in Figure 1. Hydrogen permeance increased with increasing $\mathrm{Ni}$ content. This result may be caused by the affinity of nickel for hydrogen. ${ }^{6}$ Moreover, all membranes have a high hydrogen permeance at $100^{\circ} \mathrm{C}$, with values over

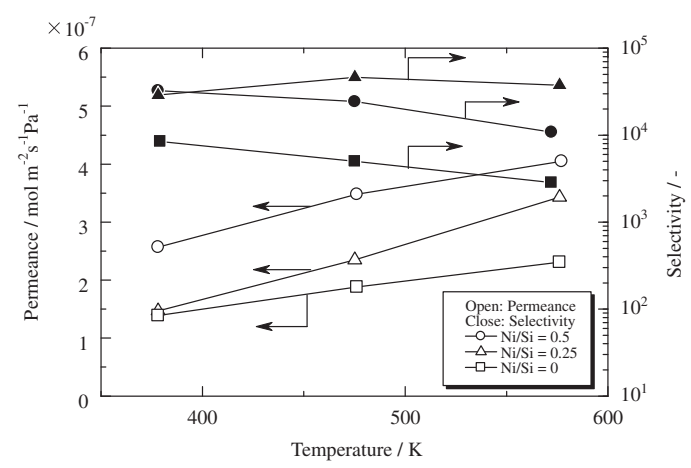

Figure 1. Effect of temperature on permeance and selectivity. 


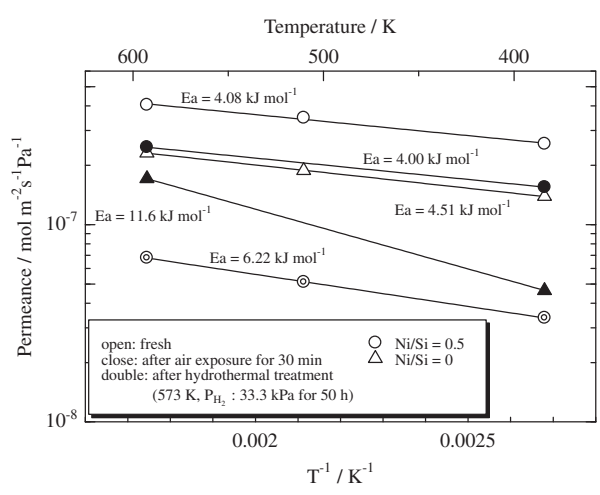

Figure 2. Effect of air exposure and hydrothermal treatment on activation energy. CVD time $=1 \mathrm{~h}$.

$1.0 \times 10^{-7} \mathrm{~mol} \mathrm{~m}^{-2} \mathrm{~s}^{-1} \mathrm{~Pa}^{-1}$. The selectivities for all membranes were over 2000 . These values may not be completely accurate, because the selectivity can be influenced by very small numbers of defects and/or pinholes. The reproducibility may need to be discussed in more detail. However, the selectivities of the Ni-doped silica membranes tend to be higher than those for nondoped silica membranes. The Ni-doping may lead to an increase in hydrogen permeance. Another reason may be the differences of pore structure in the sol-gel layer. Overall, Nidoped silica membranes led to a hydrogen permeance over $4.1 \times 10^{-7} \mathrm{~mol} \mathrm{~m}^{-2} \mathrm{~s}^{-1} \mathrm{~Pa}^{-1}$ and selectivities over 10000 at $573 \mathrm{~K}$.

The effect of air and hydrothermal treatments on the activation energies is shown in Figure 2. The activation energy for Ni-doped silica membranes, with a $\mathrm{Ni} / \mathrm{Si}$ of 0.5 (4.08 $\left.\mathrm{kJ} \mathrm{mol}^{-1}\right)$, is similar to that for the fresh silica membrane $\left(4.51 \mathrm{~kJ} \mathrm{~mol}^{-1}\right)$. After air exposure at room temperature for $40 \mathrm{~min}$, the activation energy of the silica membrane is increased from 4.5 to $11.6 \mathrm{~kJ} \mathrm{~mol}^{-1}$. The activation energy gives an indication of the silica membrane density. ${ }^{3}$ In other words, a large activation energy suggests a dense structure. Therefore, this silica membrane becomes denser in structure after exposure to air. The absolute value of hydrogen permeance decreased to $61 \%$ of the initial value. It is thought that the densification of the silica layer after air exposure is related to the decrease in hydrogen permeance. However, the activation energy for the Ni-doped silica membrane was almost constant, regardless of air exposure. Therefore, the doping of $\mathrm{Ni}$ may help prevent the densification of the silica layer, even if the silica membrane is prepared using the hybrid processing method. The hydrogen permeance of the Ni-doped silica membrane, after hydrothermal treatment, greatly decreased from $4.1 \times 10^{-7}$ to $0.68 \times 10^{-7}$ mol m$~_{-2} \mathrm{~s}^{-1}$, and the activation energy increased slightly to $6.22 \mathrm{~kJ} \mathrm{~mol}^{-1}$. This is lower than that for the silica membrane after air exposure. The doping of $\mathrm{Ni}$ may also inhibit the increase in activation energy after hydrothermal treatment. However, after the hydrothermal stability test, which was carried out at $573 \mathrm{~K}$ with $\mathrm{H}_{2}, \mathrm{CH}_{4}$ and steam feed rates of $50 \mathrm{~mL} \mathrm{~min}^{-1}$, the hydrogen permeance for the Ni-doped silica membrane decreased to $54 \%$ and $48 \%$ of initial value, after 4 and $48 \mathrm{~h}$, respectively. Although the methane permeance at $4 \mathrm{~h}$ was increased slightly from $1.94 \times 10^{-11}$ to $2.64 \times 10^{-11}$

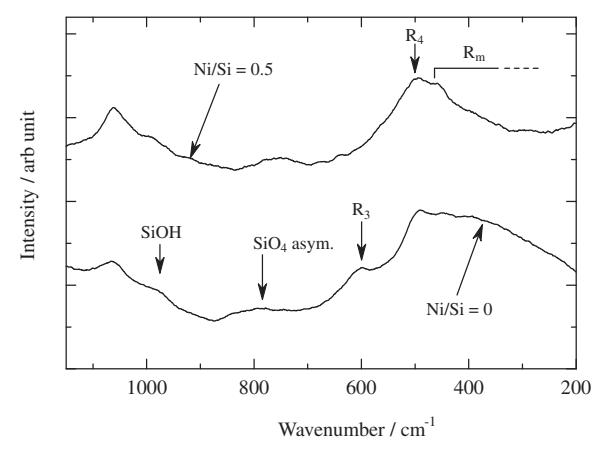

Figure 3. Raman spectra for powder samples prepared using the sol-gel method.

mol m${ }^{-2} \mathrm{~s}^{-1} \mathrm{~Pa}^{-1}$, after $48 \mathrm{~h}$, it had increased greatly to $4.04 \times$ $10^{-9} \mathrm{~mol} \mathrm{~m}^{-2} \mathrm{~s}^{-1}$. Therefore, this membrane still requires improvement for long-term hydrothermal stability.

The Raman spectra for the powder samples of silica and Nidoped silica were measured to evaluate the effect of Ni-doping in terms of chemical structure, using an NRS-3100 (JASCO). The results are shown in Figure 3. The powder samples were prepared by drying the silica and Ni-doped silica solutions under vacuum at room temperature, followed by calcination at $873 \mathrm{~K}$ for $3 \mathrm{~h}$. The sample with no Ni-doping had a band attributed to a three-membered siloxane ring $\left(\mathrm{R}_{3}\right)$, which is regarded as a structural defect. ${ }^{7}$ There were also bands observed for fourmembered $\left(\mathrm{R}_{4}\right)$ and multimembered $\left(\mathrm{R}_{\mathrm{m}}\right)$ rings in both samples. ${ }^{7}$ The $\mathrm{R}_{4}$ structure is a major component of vitreous silica. Interestingly, the $\mathrm{R}_{3}$ band was not observed in the spectrum for the Ni-doped silica. Ni-doping prevented the formation of the $\mathrm{R}_{3}$ ring. Thus, it is considered that the $\mathrm{R}_{3}$ ring is one of the factors of the activation energy increase, as a result, doping silica may suppress any increase in activation energy.

In conclusion, the Ni-doped silica membrane exhibits a high hydrogen permeance and a high selectivity under dry conditions. Moreover, an increase in activation energy was inhibited by doping with Ni. Ni-doping may prevent the formation of an $\mathrm{R}_{3}$ ring, which is considered to be a structural defect. However, the methane permeance greatly increased after $48 \mathrm{~h}$, after hydrothermal treatment. In the future, improvements in the hydrothermal stability are expected to allow the practical application of a MR.

\section{References}

1 S. Araki, N. Hino, T. Mori, S. Hikazudani, Int. J. Hydrogen Energy 2009, 34, 4727.

2 S. Gopalakrishnan, Y. Yoshino, M. Nomura, B. N. Nair, S.-I. Nakao, J. Membr. Sci. 2007, 297, 5.

3 M. Kanezashi, M. Asaeda, J. Chem. Eng. Jpn. 2005, 38, 908.

4 S. Kurungot, T. Yamaguchi, S.-i. Nakao, Catal. Lett. 2003, 86, 273.

5 S. Araki, N. Mohri, Y. Yoshimitsu, Y. Miyake, J. Membr. Sci. 2007, 290, 138.

6 Y. H. Ikuhara, H. Mori, T. Saito, Y. Iwamoto, J. Am. Ceram. Soc. 2007, 90, 546.

7 T. Nakano, N. Mura, A. Tsuzumitani, Jpn. J. Appl. Phys. 1995, 34, L1064. 